\title{
Supply Chain Collaboration
}

\author{
Ana Meca ${ }^{1}$ and Judith Timmer ${ }^{2}$ \\ ${ }^{1}$ Operations Research Center (University Miguel Hernandez), \\ 2Department of Applied Mathematics (University of Twente), \\ 1 Spain \\ 2 The Netherlands
}

\section{Introduction}

In the past, research in operations management focused on single-firm analysis. Its goal was to provide managers in practice with suitable tools to improve the performance of their firm by calculating optimal inventory quantities, among others. Nowadays, business decisions are dominated by the globalization of markets and increased competition among firms. Further, more and more products reach the customer through supply chains that are composed of independent firms. Following these trends, research in operations management has shifted its focus from single-firm analysis to multi-firm analysis, in particular to improving the efficiency and performance of supply chains under decentralized control. The main characteristics of such chains are that the firms in the chain are independent actors who try to optimize their individual objectives, and that the decisions taken by a firm do also affect the performance of the other parties in the supply chain. These interactions among firms' decisions ask for alignment and coordination of actions. Therefore, game theory, the study of situations of cooperation or conflict among heterogenous actors, is very well suited to deal with these interactions. This has been recognized by researchers in the field, since there are an ever increasing number of papers that applies tools, methods and models from game theory to supply chain problems.

The field of game theory may be divided roughly in two parts, namely non-cooperative game theory and cooperative game theory. Models in non-cooperative game theory assume that each player in the game (e.g. a firm in a supply chain) optimizes its own objective and does not care for the effect of its decisions on others. The focus is on finding optimal strategies for each player. Binding agreements among the players are not allowed. One of the main concerns when applying non-cooperative game theory to supply chains is whether some proposed coordination mechanism, or strategy, coordinates the supply chain, that is, maximizes the total joint profit of the firms in the supply chain. In contrast, cooperative game theory assumes that players can make binding agreements. Here the focus is on which coalition of players will form and which allocation of the joint worth will be used. One of the main questions when applying cooperative game theory to supply chains is whether cooperation is stable, that is, whether there exists an allocation of the joint profit among all the parties in the supply chain such that no group of them can do better on its own. Up to date, many researchers use non-cooperative game theory to analyse supply chain problems. 
This work surveys applications of cooperative game theory to supply chain management. The supply chains under consideration are so-called divergent distribution networks, which consist of a single supplier and a finite number of retailers. In particular, we focus on two important aspects of supply chain collaboration. First, we focus on inventory centralization, also called inventory pooling.

Retailers may collaborate to benefit from the centralization of their inventories. Such collaboration may lead to reduced storage costs, larger ordering power, or lower risks, for example. Models from cooperative game theory may be used to find stable allocations of the joint costs. Such allocations are important to obtain and maintain the collaboration among the retailers. There is a steady stream of papers on this subject and these are reviewed here. Second, we consider retailer-supplier relationships. Besides collaboration among retailers only, a further gain in efficiency may be obtained by collaboration between the supplier and the retailers. Also here, the question is how to reduce the joint costs. Cooperative game theory may be used to find stable allocations of the joint costs. Although a natural field to research, these problems are hardly studied by means of cooperative game theory. We review the few papers in the literature and indicate possibilities for future research.

We wish to point out that there are several other areas of cooperative games that lend themselves nicely to applications in supply chains, but that we do not review. One may think of bargaining models for negotiations among supply chain partners, network models to study multi-echelon supply chains, or coalition formation among supply chain partners, to name some themes. For bargaining models and coalition formation we refer to the review by Nagarajan \& Sošić (2006), and for theoretical issues and a framework for more general supply chain networks we refer to Slikker \& Van den Nouweland (2001).

This work is organized as follows. In section 2 we introduce some basic concepts of cooperative game theory. This helps understand how the collaboration among several agents is modelled. With this understanding, some well known results from the literature on cooperative game theory are surveyed. Thereafter we review applications of cooperative game theory to inventory centralization (section 3). Section 4 reviews and discusses retailersupplier relationships. Finally, section 5 concludes and highlights areas for future research.

\section{Cooperative game theory}

Game theory provides tools, methods and models to investigate supply chain collaboration, coordination and competition. The game theory literature can roughly be divided into cooperative and non-cooperative game theory. There are some differences between analyses using non-cooperative game theory and those using cooperative game theory. When applying non-cooperative game theory, it is assumed that each player acts individually according to its objective, and usually the mechanisms to get it are investigated. One of the main points of concern is whether the proposed mechanism provides a solution that maximizes the total supply chain profit under Nash equilibrium.

In contrast, cooperative game theory does not investigate the individual behaviour of the players explicitly and assume that once the players form a coalition, the coordination between them is achieved one way or another (i.e., either by making binding agreements and commitments or by a suitable coordination mechanism). Although cooperative games abstract from the details of mechanism that lead to cooperation, they are very powerful to investigate the problem of allocation of worth in detail. Here, the main question is whether the cooperation is stable, i.e. there are stable allocations of the total worth or cost among the 
players such that no group of them would like to leave the consortium. Cooperative game theory offers the concept of the core (Gillies, 1953) as a direct answer to that question. Nonemptiness of the core means that there exists at least one stable allocation of the total worth such that no group of players has an incentive to leave. In this chapter, we concentrate ourselves mainly on the analysis of coordination induced by cooperation (collaboration). In this approach cooperative game theory will be instrumental.

Roughly speaking, a transferable utility game (henceforth TU game) is a pair consisting of a finite set of players and a characteristic function, which measures the worth (benefit or cost) of every coalition of players, i.e. subset of the finite initial set (grand coalition), through a real valued mapping. The sub-game related to a particular coalition is the restriction of the mapping to the sub-coalitions of this coalition. A worth-sharing vector will be a real vector with as many components as the number of players in the game. The core of the TU game consists of those efficient worth-sharing vectors which allocate the worth (cost) of the grand coalition in such a way that every other coalition receives at least (or pays at most) its worth, given by the characteristic function. In the following, worth-sharing vectors belonging to the core will be called core-allocations. A TU game has a non-empty core if and only if it is balanced (see Bondareva 1963 or Shapley 1967). It is a totally balanced game if the core of every subgame is non-empty. Totally balanced games were introduced by Shapley and Shubik in the study of market games (see Shapley \& Shubik, 1969).

A population monotonic allocation scheme (see Sprumont 1990), or pmas, for a TU game guarantees that once a coalition has decided upon an allocation of its worth, no player will ever be tempted to induce the formation of a smaller coalition by using his bargaining skills or by any others means. It is a collection of worth-sharing vectors for every sub-game satisfying efficiency property and requiring that the worth to every player increases (or decreases) as the coalition to which it belongs grows larger. Note that the set of worthsharing vectors that can be reached through a pmas can be seen as a refinement of the core. Every TU game with pmas is totally balanced.

A game is said to be super-additive (or sub-additive) if it is always beneficial for two disjoint coalitions to cooperate and form a larger coalition. Balanced TU games might not be superadditive (sub-additive), but they always satisfy super-additive (sub-additive) inequalities involving the grand coalition. However, totally balanced TU games are super-additive (subadditive). A well-known class of balanced and super-additive (sub-additive) games is the class of convex (concave) games. A TU game is said to be convex if the incentives for joining a coalition increase as the coalition grows, so that one might expect a "snowballing" effect when the game is played cooperatively (Shapley, 1971).

Another class of balanced and super-additive (sub-additive) games is the class of permutationally convex (concave) games (Granot \& Huberman, 1982). A game is permutationally convex (concave) if and only if there exists an ordering of the players for the grand coalition such that the game is permutationally convex (concave) with respect to this ordering. Granot \& Huberman (1982) showed that every permutationally concave TU game is balanced.

A worth allocation rule for TU games, is a map which assigns to every TU game a worthsharing vector. One example of such a worth allocation rule is the proportional rule. This proportional division mechanism allocates the worth of the grand coalition in a proportional way according to a fixed proportionality factor (e.g., the individual worth for each player). 


\section{Inventory centralization}

Generally speaking, shops or retailers trade various types of goods, and to keep their service to their customers at a high level they aim at meeting the demand for all goods on time. To attain this goal, retailers may keep inventories in a private warehouse. These inventories bring costs along with them. To keep these costs low, a good management of the inventories is needed. The management of inventory, or inventory management, started at the beginning of this century when manufacturing industries and engineering grew rapidly. To the best of our knowledge, a starting paper on mathematical models of inventory management was Harris (1913). Since then, many books on this subject have been published. For example, Hadley \& Whitin (1963), Hax \& Candea (1984), Tersine (1994), and Zipkin (2000). Most often, the objective of inventory management is to minimize the average cost per time unit (in the long run) incurred by the inventory system, while guaranteeing a prespecified minimal level of service.

In this section, we review the literature and study the applications of cooperative game theory to inventory centralization in supply chains. The supply chains that we focus on along this work are divergent distribution networks that consist of a supplier and a finite number of retailers. The main motivation behind using a cooperative game is that it allows us to establish a framework to examine the effect of coordinated ordering/holding by the retailers, which generates some joint worth (benefit or cost), using cooperative game theory solutions across several structurally different inventory centralization models. The main focus of concern is how to allocate the worth among the retailers. In doing so, we try to find stable allocations of worth, which is important for the existence and stability of the cooperation.

In this study, we primarily focus on coordination in continuous review inventory situations. In this framework, the class of inventory games arises when considering the possibility of joint ordering, and holding, in n-person Economic Order Quantity (or Economic Production Quantity) inventory situations in order to reduce the total inventory costs. The underlying Operation Research problems are the well-known EOQ (EPQ) situations, which were already introduced by Harris (1915). In these continuous time models with infinite horizon it is assumed that a single retailer faces a constant demand rate with the objective of minimizing its inventory costs.

A natural extension of this model is to consider now coordination in the classical WagnerWhitin problem (see Wagner \& Whitin 1958). It can be seen as a periodic version of the above model with finite horizon and time varying demand. Here new types of production/ inventory games arise when a collection of retailers tries to minimize their total inventory costs by joint ordering/holding. All of them make up the class of dynamic inventory games. Finally, we pay attention to coordination in a multiple newsvendor setting. The newsvendor model is first introduced by Arrow et al. (1951) and it was originated by the story of a newsboy who faces random demand and has to decide everyday how many newspapers to buy to maximize his expected profit. The newsvendor models are often used to support decision making in several situations with highly perishable products or products with short life cycle. The focus of this study is the inventory centralization in newsvendor environments. Newsvendor games arise when a finite number of stores (newsvendors) respond to a periodic random demand (of newspapers) by ordering jointly at the start of every period. Their main objective is to minimize the resulting expected cost. 
This section is organized as follows. We first provide an overview of inventory games in subsection 3.1. Thereafter the class of dynamic inventory games arises as a natural extension of the former (subsection 3.2). Finally, newsvendor games are analyzed and surveyed in subsection 3.3.

\subsection{Inventory games}

Inventory situations, introduced in Meca et al. (2004), study how a collective of retailers can reduce its joint inventory costs by means of cooperative behaviour. Depending on the information revealed by each individual retailer, the authors analyze two related cooperative games: inventory cost games and holding cost games. For both classes of games, they focus on proportional division mechanisms to share the joint cost.

In an inventory cost game, a group of retailers dealing with the ordering and holding of a certain commodity (every individual agent's problem being an EOQ problem), decide to cooperate and jointly make their orders. To coordinate the ordering policy of the retailers, some revelation of information is needed: the amount of revealed information between the retailers is kept as low as possible since they may be competitors on the consumer market. However, in a holding cost game coordination with regard to holding cost is considered. In this case full disclosure of information is needed. These kinds of cooperation are not unusual in the economic world: for instance, pharmacies usually form groups that order and share storage space. Meca et al. (2004) introduce and characterize the SOC-rule (Share the Ordering Costs) as a core-allocation for inventory cost games, and Meca et al. (2003) revisit inventory cost games and the SOC-rule. There it is shown that the wider class of n-person EPQ inventory situations with shortages leads to exactly the same class of cost games. Moreover, an alternative characterization of the SOC-rule is provided there. Mosquera et al. (2007) introduce the property of immunity to coalition manipulation and demonstrate that the SOC-rule is the unique solution for inventory cost games that satisfies this property. In addition, Meca et al. (2004) shows that holding cost games are permutationally concave. Moreover, the demand proportional rule leads to a core-allocation of the corresponding game that can even be sustained as a pmas.

Later, Meca (2007) completes the study of holding cost games. A more general class of inventory games, inspired by the aforementioned ones, is presented in that paper, namely the so-called generalized holding cost games. It is shown that generalized holding cost games and all their subgames are permutationally concave; hence generalized holding cost games are totally balanced. Thereafter the author focuses on the study of a core-allocation family which is called N-rational solution family. It is shown that a particular relation of inclusion exists between the above family and the core. Finally a new proportional rule called minimum square proportional rule is studied, which is an N-rational solution.

On the other hand, Toledo (2002) analyzes the class of inventory games that arises from inventory problems with special sale prices. A collective of retailers trying to minimize its joint inventory cost by means of cooperation may receive a special discount on set-up cost just in ordering. Reasons for such a price reduction range from competitive price wars to attempted inventory reduction by the supplier. Each retailer has its own set-up cost which is invariant to the order size. Meca et al. (2007) assume that when an order is being placed, it is revealed that the supplier makes a special offer for the next order. Notice that the above condition makes sense from an economic point of view since if one retailer is a very good client then the supplier himself would benefit by giving the client preferential treatment. 
Cooperation among retailers is given by sharing the order process and warehouse facilities: retailers in a coalition make their orders jointly and store their inventory in the cheapest warehouse. This cooperative situation generates the class of inventory games with non discriminatory temporary discounts. This new class of games motivates the study of a more general class of TU games, namely p-additive games. It contains the class of inventory games with non discriminatory temporary discounts as well as the class of inventory cost games (Meca et al. 2003). Meca et al. (2007) shows that p-additive games are totally balanced. They also focus on studying the character concave or convex and monotone of $\mathrm{p}$ additive games. In addition, the modified SOC-rule is proposed as a solution for $\mathrm{p}$-additive games. This solution is suitable for $\mathrm{p}$-additive games since it is a core-allocation, which can be reached through a pmas. Moreover, two characterizations of the modified SOC-rule are provided.

Tijs et al. (2005) study a situation where one agent has an amount of storage space available and the other agents have some goods, part of which can be stored generating benefits. The problem of sharing the benefits produced by full cooperation between agents is tackled in this paper, by introducing a related cooperative game. This game turns out to be a big boss game with interesting theoretical properties. A solution concept, relying on optimal storage plans and associated holding prices, is also introduced, and its relationship with the core of the above holding game is explored in detail. The family of monotonic decreasing bijective mappings, defined on the set of non-negative real numbers, plays an important role in their approach.

An interesting addition to Inventory Games (as its authors claim) is the paper Hartman \& Dror (2007). Its point of departure is the inventory cost game described in Meca et al. (2004). The former paper examines a collaborative procurement for the EOQ model with multiple items (items are considered as good types or types of commodities). The authors consider an inventory model with joint ordering in which the cost of ordering an item has two separable components- a fixed cost independent of the item type, and an item specific cost. They address two questions: what items should be ordered together, and how to share the ordering costs among the different items. Then they prove that consolidation of all the items is cheaper if there are fair cost allocations (the core of the game is non-empty). It happens when the portion of the ordering cost common to all items is not too small. They further show how sensitive the non-empty core is to adjustments in the cost parameters.

Finally, another appealing contribution to Inventory Games is the joint replenishment games with a submodular joint setup cost function proposed by Zhang (2007). The author shows that this game is balanced. He also shows that a special case of this game is concave, which generalizes one of the main results of Anily \& Haviv (2006).

\subsection{Dynamic inventory games}

As mentioned before, one of the main objectives of the retailers is cost reduction. In order to achieve this goal, groups of retailers tend to form coalitions to decrease operation costs by making dynamic decisions throughout a finite planning horizon. In tactical planning of enterprises that produce indivisible goods, operation costs mainly consist of production, inventory-holding, and backlogging costs. These coalitions should induce individual and collective cost reductions; thus, stability is achieved in the process of enterprise cooperation. In our framework a coalition allows each of its members to have access to the technologies owned by the other members of the coalition. Thus, members of a coalition can use the 
lowest-cost technology of the retailers in the coalition. Planning is done throughout a finite time horizon; at the beginning of each period, the costs to the members of a coalition, which depend on the best technology at that point, may change.

The model that represents such a situation is the dynamic, discrete, finite planning horizon production-inventory problem with backlogging. The objective of any group of retailers is to satisfy the demand for indivisible goods in each period at a minimum cost. This is a wellknown combinatorial optimization problem for which the algorithm by Wagner \& Whitin provides optimal solutions by dynamic programming techniques. The optimal solutions of this problem lead to the best production-inventory policy for the group of retailers. These policies generate an optimal operation cost for the entire group. The question is what portion of this cost is to be supported by each retailer. Cooperative game theory provides the natural tools for answering this question.

The study of cooperative combinatorial optimization games, which are defined through characteristic functions given as optimal values of combinatorial optimization problems, is a fruitful topic (see for instance Shapley \& Shubik, 1972, Dubey \& Shapley, 1984, Granot, 1986, Tamir, 1992, Deng et al. 1999 and 2000, and Faigle \& Kern, 2000). There are characterizations of the total balancedness of several classes of these games. Inventory games and combinatorial optimization games are, up to date, disjoint classes of games. While in the former class there is always an explicit form for the characteristic function of each game, the characteristic function of the games in the latter class it is defined implicitly as the optimal value of an optimization problem in integer variables.

Guardiola et al. (2007a) introduce a class of production-inventory games that combines the characteristics of inventory and combinatorial optimization games: this class models cooperation on production and storage of indivisible goods and its characteristic function is defined implicitly as the optimal value of a combinatorial optimization problem. It turns out to be a new class of totally balanced combinatorial optimization games.

Further, the authors consider a group of agents, each one facing a PI-problem, that decide to cooperate to reduce costs, and then a production-inventory situation (henceforth, PIsituation) arises. Then, for each PI-situation, the corresponding cooperative game structure, namely production-inventory game (henceforth, PI-game), is defined. The main results are total balancedness and an explicit form for the characteristic function. The study of PI-games is completed by showing that the Owen set of a PI-situation (the set of allocations that are achievable through dual solutions, see Owen 1975 and Gellekom et al. 2000) shrinks to a singleton: the Owen point. This fact motivates the name Owen point rather than Owen set within this class of games. Guardiola et al. (2007a) propose the Owen point as a coreallocation for a PI-game which is easy to calculate and satisfies good properties. Its explicit form is also provided, and moreover, it is proved that the Owen point can be reached through a pmas. Hence, every PI-game is a non-negative cost game allowing for pmases (henceforth, PMAS-game). In addition, a necessary and sufficient condition for the core of a PI-game to be a singleton: the Owen point is presented. Finally, the authors point out the relationship of the Owen point with some well-known worth allocation rules in cooperative game theory.

Later, Guardiola et al. (2007b) prove that the class of PI-games coincides with the class of PMAS-games, and they provide an interesting relationship between PI-games and concave games. In addition, they present three different axiomatic characterizations of the Owen point. To achieve the two first characterizations they have kept in mind the work by 
Gellekom et al. (2000) in which the Owen set of linear production games is characterized. The third one, which is based on a population monotonic property, is very natural due to the fact that the class of PI-games coincides with the class of non-negative cost games with a pmas.

The study of coordination in periodic review inventory situations is completed by Guardiola et al. (2006). They consider systems composed by several retailers where each of them has four types of costs: ordering, purchasing, inventory holding and backlogging costs. It is assumed that each single component in the system is the backlogging extension of the wellknown Wagner \& Whitin model, which Zangwill (1969) solved by dynamic programming techniques. In their approach coordination means that retailers share their holding technologies and ordering channels. Therefore, when a coalition of retailers is to form (joint venture) each retailer works with the best holding technology and ordering channels among the members of the coalition. This means that the members of that coalition purchase, hold inventory, pay backlogged demand and make orders at the minimum cost of the coalition members. Cooperation in holding and purchasing is usual and has appeared already in literature. Their mode of cooperation in backlogging is also standard although new: once a coalition is formed, all its members pay compensation to customers for delayed delivering (backlogging cost) of their demands according to the cheapest cost among the members in the coalition. In some regard, larger coalitions are stronger and can "squeeze" their clients a bit more. It is obvious that the above coordination process induces savings and therefore, studying the problem of how to allocate the overall saving among the retailers is a meaningful problem. Once again this allocation problem can be modelled by a transferable utility cooperative game. In this game the characteristic value of each coalition of retailers is obtained solving the combinatorial optimization problem that results from Zangwill's model induced by the members of the coalition.

Closer to Guardiola et al. $(2006,2007 a)$ are papers that focus on cooperation in periodic review inventory situations by means of cooperative game theory. One of the papers to do so is Van den Heuvel et al. (2007), which studies coordination in economic lot sizing situations (henceforth, ELS-situations). In that finite horizon model, players should satisfy the demand in each period by producing in that period or carrying inventory from previous periods; backlogging is not allowed. The main difference between that model and the one given by Guardiola et al. (2007a) is that the former considers setup costs but assumes that costs are the same for all players in every period. Therefore, ELS- and PI-situations are pairwise distinct, in general. The main result in Van den Heuvel et al. (2007) is that ELSgames (games induced by ELS-situations) have a nonempty core. In another paper, Chen \& Zhang (2007a) propose an integer programming formulation for the concave minimization problem that results from an ELS-situation and show that its linear programming (LP) relaxation admits zero integral gaps, which makes it possible to analyze the game by using LP duality. Here the dual variables are interpreted as the price of the demand per unit.

Guardiola et al. (2006) study a new model of coordination in inventory problems where a group of retailers place periodical orders of indivisible goods considering setup, purchasing, holding and backlogging costs. It leads to a new class of totally balanced combinatorial optimization games called setup-inventory games (henceforth, SI-games). SI-games extend PI-games since the latter do not include setup costs. Notice that if setup cost were zero in all periods, then a PI-situation would arise. SI-games also extend ELS-games since all costs considered can be different for several players in every period and backorders are allowed. 
However, ELS-games with concave ordering cost function (see Chen \& Zhang, 2007a) do not extend SI-games since, as the former consider a more general ordering cost function, the latter assume that all costs can be different.

All of these characteristics make the model in this paper richer than the previous ones although it is harder to analyze. Guardiola et al. (2006) prove that cooperation in periodic review inventory situations is always stable, i.e. every SI-game has a nonempty core. In addition, they introduce a new family of cost allocations on the class of SI-games: the parametric extended Owen points. It is proven that, under certain conditions, a particular core-allocation can be found (within the parametric family of extended Owen points) for the corresponding SI-game. This point also introduces an important difference with Van den Heuvel et al. (2007), and Chen \& Zhang (2007a), who show that ELS-games have a nonempty core, but do not provide any core-allocation.

\subsection{Newsvendor games}

In a newsvendor setting, the retailers might benefit from cooperation through coordinated ordering and inventory centralization. The cooperation here can be described as follows: the retailers place joint orders for goods to satisfy the total demand they are faced with. In this way, they could get some benefit from coordination of the others and perfect allocation of the ordered amount to the demands realize.

There are several papers that focus on cooperation in inventory centralization in newsvendor settings. One of the pioneers to do so is Eppen (1979), which studies the effects of centralization for inventory models with random demand for each store. He assumes identical storage and penalty costs for each store and in the centralized location, and shows that in this case savings always occur. However, for general demand distributions and store specific holding and penalty costs there might not be any savings from centralization. Conditions on demand distributions are discussed in Chen \& Lin (1989) and on holding and penalty costs in Hartman \& Dror (2005).

Gerchak \& Gupta (1991) investigate a newsvendor game in which each retailer is a newsvendor with identical cost structures and the transportation cost associated with reallocating inventory after observing the demand is ignored. Hartman et al. (2000) study models with identical newsvendors, focusing especially on the core of newsvendor games. They prove the non-emptiness of the core of these games under some restrictive assumptions on demand distributions: symmetric and joint multivariate normal distribution. Müller et al. (2002) and Slikker et al. (2001) independently develop a more general result, showing that newsvendor games have a non-empty core regardless of the demand distribution. Müller et al. (2002) also provide conditions under which the core is a singleton. The above non-emptiness result is still valid even when there are infinitely many retailers, as proved by Montrucchio \& Scarsini (2007). Slikker et al. (2005) enrich the finite model by allowing the retailers to use transhipment (at a positive cost) after demand realization is known. The authors show that newsvendor games with transhipments have a non-empty core even if the retailers have different retail and wholesale prices. Moreover, newsvendor games are not convex in general. Ozen et al (2005) study the convexity of newsvendor games under special assumptions about the demand distributions. Their analysis focus on the class of newsvendor games with independent symmetric unimodal demand distributions. Several interesting subclasses, which only contain convex games, are 
identified. Additionally, the authors illustrate that these results cannot be extended to all games in this class.

In several papers, Hartman and Dror analyze cooperation through inventory centralization in a newsvendor setting. Hartman \& Dror (2003) study the cost game among the retailers with normally distributed and correlated individual demands. Hartman \& Dror (2005) analyze a model of inventory centralization for a finite number of retailers facing random correlated demands. They consider two different games: one based on expected costs (benefits), and the other based on demand realizations. The authors show that, for the first game, the core is non empty when holding and shortage costs are identical for all coalitions of retailers, and demand is normally distributed. However, the core might be empty when the retailers' holding and penalty costs differ; they derive conditions under which such a game will be subadditive. For the second game, the core can be empty even when the retailers are identical.

There are other papers which examine the existence of stable profit allocations among cooperative retailers by means of the so called stochastic cooperative decision situations (see Ozen, 2007). Ozen et al (2006) analyze the stability of cooperation among several outlets who come together to benefit from inventory centralization. The authors focus on newsvendor situations with delivery restrictions. In these situations, the retailers dispose some restrictions on the number of items that should be delivered to them if they join a coalition to benefit from joint ordering. They show that the associated cooperative game has a nonempty core. Afterwards, they concentrate on a dynamic situation where the retailers change their delivery restrictions. They then investigate how the profit allocation might be affected by these changes. Another example of newsvendor situations is considered in Ozen et al (2007). They study newsvendor situations with multiple warehouses, where the retailers can cooperate to benefit from inventory pooling. The warehouses offer alternative ways of supplying the goods to the retailers, which might become more useful when the retailers form coalitions. The authors study the corresponding cooperative game and they prove that the core of these games is nonempty. In the previous papers, the cooperation among retailers through the coordination of their orders and allocation of these orders after demand realization has been considered. Sometimes, however, it may not be possible to allocate the orders after exact demand realizations. In such situations, the retailers can only satisfy their customers from the stock at their local facilities. However, if the retailers could obtain better information about future demand while their orders are on the way, they would still be able to benefit from inventory centralization by reallocating their orders when they arrive at the facility where the reallocation can take place after demand information update (e.g., port, warehouse, etc.). Ozen \& Sosic (2006) consider newsvendor situations with updated demand distribution. They investigate the associated cooperatives games between the retailers and show that such games are balanced.

A very recent paper by Chen \& Zhang (2007b) presents a unified approach to analyze the newsvendor games using the duality theory of stochastic programming developed by Rockafellar \& Wets (1976). The optimizations problems corresponding to the newsvendor games are formulated as stochastic programs. The authors observe that the strong duality of stochastic linear programming not only directly leads to the non-emptiness of the cores of such games, but also suggests a way to find a core-allocation. The proposed approach is also applied to newsvendor games with concave ordering cost. Additionally, they prove that it is 
NP-hard to determine whether a given allocation is in the core of the newsvendor games even in a very simple setting.

The newsvendor inventory centralization problem examined in the literature is geared mainly to the expected value cost analysis. However, minimizing expected centralized inventory cost might not be a very convincing argument for centralization. A build-in cost allocation mechanism should provide additional incentives for cooperation. That is, in each time period the stores reflect on the actual performance of the system in relation to the anticipated long-run expected performance. The analysis of an on-line system cost allocation(s) performance versus the performance in expectation is the main topic of Dror, et al (2007). They examine a related inventory centralization game based on demand realizations that has, in general, an empty core even with identical penalty and holding costs (Hartman \& Dror, 2005). They then propose a repeated cost allocation scheme for dynamic realization games based on allocation processes introduced by Lehrer (2002). It is proven that the cost sub-sequences of the dynamic realization game process, based on Lehrer's rules, converge almost surely to either a least square value or the core of the expected game. To complete this study, they extend the above results to more general dynamic cost games and relax the independence hypothesis of the sequence of players' demands at different stages.

\section{Retailer-supplier relationships}

The previous section discussed cooperation among retailers only, or in other words, horizontal cooperation within a supply chain. This type of cooperation is concerned with collaboration among parties in a chain that are on the same level and perform similar tasks. This section concentrates on vertical cooperation, that is, collaboration among parties in a chain that are on adjacent levels, like a supplier and retailer. Hence, these parties perform different tasks, which ask for another type of cooperation than in case of horizontal cooperation. Important aspects of cooperation include the coordination of actions to maximize joint profits.

Vertical cooperation within a supply chain may take different forms ranging from the coordination of actions to a full merger of the parties involved. In the first case, coordination of actions, the parties remain economically independent and act under decentralized control, that is, each party takes its own decision. Nevertheless, the coordination that the parties agreed upon makes sure that each of them improves upon its profits. Because of decentralized control and the conflicts of interests, these situations are often studied with non-cooperative game theory. We refer the reader to Cachon \& Netessine (2004) for a review on this area of research. A merger of parties is another extreme with regard to vertical cooperation. In this case, all parties give up their independence and will be under centralized control. The new merger decides upon actions for all (former) parties. Such a merger will only be formed if there is a win-win situation for all of the parties.

In all cases, parties or firms in a chain are only willing to cooperate if none of them can do better otherwise. A natural tool to study this is cooperative game theory. In particular TUgames are useful to decide whether cooperation is stable and how to maintain it by means of some allocation of the joint profits among the parties involved. It is surprising to learn that only a few papers study vertical cooperation in a supply chain by means of cooperative game theory, and by TU-games in particular. Therefore, we believe that it is a new and exciting area of research on supply chains. 
Within cooperative game theory, bargaining games are the most popular tools to study cooperation among supply chain partners. There are two recent reviews that pay attention to bargaining models. Sarmah et al. (2006) provide a review on supplier-retailer models in supply chain management. The authors focus on coordination models in supply chain management that use quantity discounts as a coordination tool in a deterministic environment. The only cooperative coordination models mentioned are the cooperative bargaining games. All other coordination models are studied with non-cooperative game theory. Another review by Nagarajan \& Sošić (2006) also considers cooperation among supply chain partners. They focus on two important aspects of cooperative games, namely on profit allocation and stability. First, attention is payed to bargaining games for profit allocation. Thereafter, coalition formation among parties in a supply chain is surveyed.

As far as we are aware, the only paper that uses TU-games to study vertical cooperation in a supply chain is Guardiola, Meca and Timmer (2007). In this paper, distribution supply chains with one supplier and multiple retailers under decentralized control are studied. Cooperative TU-games are used to study the stability and the gains of cooperation. Cooperating retailers may gain from quantity discounts, while a supplier-retailer cooperation results in reduced costs. The authors show that the corresponding TU-games are balanced, that is, cooperation is stable. They also propose a specific allocation of the joint profit that always belongs to the core of the game. This does not hold for the Shapley value, a well-known solution for TU-games. Another property of the proposed allocation is that properly valuates the supplier since it is indispensable to obtain a maximal gain in profits.

\section{Conclusion and future research}

In this chaper, we have reviewed and surveyed the literature on supply chain collaboration. As mentioned above, the game theory models that include cooperative behaviour among retailers seem to be a natural framework to model cooperation (collaboration) in supply chains that consist of a supplier and a finite number of retailers. Various researchers in this area have already adopted several cooperative models dealing with supply chain coordination, and it is expected to see many more in the near future since, as you may notice, this is a rather new area of research in supply chain management.

One level of supply chain collaboration is the inventory centralization. The main focus of concern here is to examine the effects of horizontal cooperation (cooperation among the retailers only). The first step is to study cooperation in continuous review inventory situations through out the class of inventory games. We can conclude that any collective of retailers can reduce its joint inventory costs by means of cooperative behaviour. Additionally, they can always find stable (core-allocations) and consistent (sustained as pmases) allocation rules, which therefore encourages them not to form sub-coalitions during the cooperative process. This wide class of games arises when considering joint ordeing and holding in the basic inventory situations (EOQ and EPQ). Some nice additons to this umbrella of games are the holding games introduced by Tijs et al (2005), and the collaborative procurement for the EOQ model with multiple items proposed by Hartmand \& Dror (2007). There are numerous oportunities to create new inventory centralization models that extend the ones already studied and can be included in the class of inventory games. We hope to see and, why not, do many more in the future.

The second step is to consider the dynamic extension of inventory games. It is the periodic version of the above model with finite horizon and time varying demand. Several papers in 
the field have analyzed cooperation in finite horizon periodic review inventory situations (see Guardiola et al. 2007a,b, Van Den Heuvel et al. 2007, and Chen \& Zhang, 2007a). Nevertheless, those papers only consider partial aspects of the general problem. In Guardiola et al. (2006) a new model is introduced that incorporates all relevant costs and that, in some sense, includes the models in the above references as particular instances. In their model agents share ordering channels and holding and backlogging technologies so that the resulting coordination inventory model induces savings. These savings can be distributed among any group of agents in a stable way since the corresponding cooperative game is totally balanced. Moreover, for this class of games (SI-games), the authors define a parametric family of allocations that extends the rationale behind the Owen point (see Guardiola et al. 2007a,b) and identify an important subclass of SI-games where an extended Owen point can be attained by means of a pmas.

In some respects Guardiola et al. (2006) unifies the treatment of coordination in periodic review inventory situations (all relevant costs are included). In addition, it proves that this type of coordination makes sense since induces savings that can be allocated without being blocked by any member of the group (the cooperative game induced by the model is totally balanced). This stability is rather appealing and invites to pursue new investigations that increase efficiency in coordinated models of inventory operation. Some of these additional topics for further research are: (1) investigating coordination in dynamic inventory situations with concave cost functions; and (2) exploring new models of periodic review inventory problems with shipping costs.

The third step we centre our attention on presenting cooperation in multiple newsvendor settings. In such frameworks, newsvendor games arise and are studied. The main result here is that the retailers can always get some benefit from cooperation through coordinated ordering and inventory centralization. In addition, there always exist stable profit allocations among cooperative retailers. However, the problem of determining whether a given allocation is stable or not is sometimes an NP-hard optimization problem even in a very simple newsvendor setting.

A different type of collaboration is vertical cooperation in supply chains. Most of the literature up-to-date studies a supplier-retailer with non-cooperative game theory. For a proper analysis of all cooperation possibilities, the application of cooperative game theory is necessary. This is a rather new area of research with a limited number of papers. Most of these use bargaining games to study negotiations and profit allocation between the supplier and the retailer. As far as we are aware, only Guardiola et al., (2007) use TU-games to study collaboration in a distribution chain with a single supplier and multiple retailers. This new area of research has lots to explore yet. TU-games can be used to analyse stability of collaboration within all sorts of supplier-retailer relationships. Further, aspects like nonzero leadtime, stochastic demand, and incomplete availability of information on costs should be included. Other interesting research includes situations in which the retailers provided by the supplier are competitors on the same market, or situations of collaboration within a supply chain that involves three or more levels, like a manufacturer, supplier and a retailer. Other than the ones already mentioned, some other ongoing and future research topics in supply chain collaboration are presented below. 


\subsection{Cooperation in multi-supplier supply chains with bounded demand}

In this section, we propose to exted the study of retailer-supplier relationships in supply chains with a finite number of suppliers and retailers, and random demands. The main focus of concern is to analyze the impact of such cooperation on the suppliers, retailers, and supplier-retailer interactions.

The starting point is the paper Guardiola et al., (2007) that, as we already announced, studies the coordination of actions and the allocation of profit in supply chains under decentralized control in which a single supplier supplies several retailers with goods for replenishment of stocks. In our multi-supplier and bounded demand framework, the main goal of the suppliers and the retailers is also to maximize their individual profits. Since the outcome under decentralized control is inefficient, cooperation among firms by means of coordination of actions may improve the individual profits. Cooperation is studied by means of cooperative game theory. First, we examine whether or not the cooperative game corresponding to this multi-supplier and bounded demand situation is balanced. Then we will look for an (stable) allocation rule that satisfies good properties for these games.

\subsection{Cooperation in assembly systems: the role of knowledge sharing}

In this section, we analyze a production system similar to that of Toyota. Based on this model, we investigate the costs, benefits, and challenges associated with establishing a Knowledge Sharing Network (see Dyer \& Hatch 2004).

We consider an assembly system with one assembler (for example, Toyota) purchasing components from several suppliers. Demand is deterministic and each supplier faces holding and fixed ordering costs (i.e., a stationary model, not necessarily time-dependent). For a given set of costs and demand rates, there is no exact solution, but one can construct a solution that is very close to optimal (see Zipkin, 2000). This model has some similarities both with Guardiola et al. (2007a) and Meca et al. (2004).

We model process improvement by considering reductions in the fixed costs. In a knowledge sharing network, suppliers are placed in groups to share knowledge about best practices. In our setting, suppliers within each group achieve, through knowledge transfer, a fixed cost equal to that of the supplier with the lowest fixed cost in the group. This idea is similar to that proposed in Guardiola et al. (2007a), in which all firms incur the fixed cost of the most efficient company.

We model knowledge transfer through a cooperative game and focus on reductions in fixed costs. In this setting, we explore the feasibility of knowledge sharing, by investigating the existence of payment transfers that make all firms better off with cooperation (i.e., the core of the corresponding game is non-empty). In addition, if the core is non-empty, we study properties of the core and compute core-allocations.

\section{References}

Anily, S. and Haviv, M. (2006). "The Cost Allocation problem for the First Order Interaction Joint Replenishment Model”, Operations Research 55 (2), 292-302.

Arrow, K.J., Harris, T., and Marschak, J. (1951). "Optimal inventory policy," Econometrica 19, 250-272. 
Bondareva, O.N. (1963). “Applications of Linear Programming Methods to the Theory of Cooperative Games" (in Russian), Problemy Kibernety 10, 119--139.

Borm, P.E.M., Hamers, H., and Hendrickx, R. (2001). “Operations Research Games: A Survey, “ TOP 9, 139-216.

Cachon, G., Netessine, S. (2004) Game theory in supply chain analysis. In: Simchi-Levi, Dl, Wu, S.D., Shen, M. (eds), Supply chain analysis in the eBusiness era. Kluwer.

Chen, M.S. and C.T. Lin (1989). "Effects of Centralization on Expected Costs in a Multilocation Newsboy Problem", Journal of the Operational Research Society 40, 597602.

Chen, X. and Zhang, J. (2007a). "Duality approaches to economic lot sizing games," Operations Research, revised and resubmitted, July 2007.

Chen, X. and Zhang, J. (2007b). "A stochastic programming duality approach to inventory centralization games," Operations Research, minor revision submitted, September 2007.

Deng, X., Ibaraki, T., and Nagamochi, H. (1999). "Algorithmic aspect of the core of combinatorial optimization games, " Math.Oper. Res. 24, 751-766.

Deng, X., Ibaraki, T., Nagamochi, H., and Zang, W. (2000). “Totally balanced combinatorial optimization games, " Math. Programming 87, 441-452.

Dror, M., Guardiola, L.A., Meca, A. and Puerto, J. (2007). "Dynamic Realization Games in Newsvendor Inventory Centralization," International Journal of Game Theory (Online first).

Dubey, P. and Shapley, L.S. (1984). “Totally balanced games arising from controlled programming problems, " Math. Programming 29, 245-267.

Dyer, J.H. and Hatch, N.W. (2004). "Using Supplier Networks to Learn Faster," Mit Sloan Management Review 57-63.

Eppen, G.D. (1979). “Effect of Centralization on Expected Cost in a Multi-location Newsboy Problem, " Manage. Sci. 25, 498-501.

Faigle, U. and Kern, W. (2000). "On the core of ordered submodular cost games, " Math. Programming 87, 483-499.

Gellekom, J.R.G., Potters, J.A.M., Reijnierse, J.H., Engel, M.C., and Tijs, S.H. (2000). "Characterization of the Owen Set of Linear Production Processes," Games Econ. Behav. 32, 139-156.

Gerchak, Y. and Gupta, D. (1991). 'On Apportioning Costs to Customers in Centralized Continuous Review Inventory Systems," J. Oper. Manage. 10, 546-551.

Gillies, D.B. (1953). “Some Theorems on N-person Games. Ph.D. Dissertation, Department of Mathematics", Princeton University.

Granot, D. (1986). "A generalized linear production model: A unified model”, Math. Programming 34, 212-222.

Granot, D.G. and Huberman, G. (1982). “The relation between convex games and minimal cost spanning tree games: a case for permutationally convex games," SIAM Journal of Algebraic and Discrete Methods 3:288-292 
Guardiola, L.A., Meca, A. and Puerto, J. (2006). "Coordination in periodic review inventory situations,". Trabajos de I+D I-2006-13, CIO Universidad Miguel Hernández, Elche. Submitted.

Guardiola, L.A., Meca, A., Puerto, J. (2007a). "Production-Inventory games: a new class of totally balanced combinatorial optimization games," Games and Economic Behaviour (Online March 30, 2007).

Guardiola, L.A., Meca, A., Puerto, J. (2007b). "PI-games and pmas games: characterizations of Owen point," Forthcoming in Mathematical Social Sciences

Guardiola, L.A., Meca A., and Timmer J. (2007) "Cooperation and profit allocation in distribution chains," Decision Support System 44, 17-27.

Hadley, G. and Whitin, T.M. (1963). "Analysis of Inventory Systems," Prentice-Hall, Englewood Cliffs, N.J.

Harris, F. (1913). "How many parts to make at once," Factory, The Magazine of Management 10, 135-136, 152.

Harris, F. (1915). “Operations and Cost,” Factory Management Series, A.W. Shaw, Chicago, 48-52.

Hartman, B.C., Dror, M. (2003). “Optimizing centralized inventory operations in a cooperative game theory seting", IIE Trans. 35, 243-257.

Hartman, B.C., Dror, M. (2005). "Allocation of gains from inventory centralization in newsvendor environments", IIE Trans. 37, 93-107.

Hartman, B.C., Dror. M., Shaked, M. (2000). "Cores of inventory centralization games", Games Econ. Behav. 31, 26-49.

Hartman B.C. and Dror M. (2007). "Shipment consolidation: who pays for it and how much?" Management Science 53 (1), pp 78-87.

Hax, A.C. and Candea, D. (1984). "Production and Inventory Management," Prentice-Hall, Englewood Cliffs, N.J.

Lehrer, E., (2002). "Allocation process in cooperative games", International Journal of Game Theory 31, 341-351.

Meca, A., García-Jurado, I. and Borm, P.E.M. (2003). "Cooperation and competition in Inventory Games," Mathematics Methods of Operation Research 57, 481-493.

Meca, A., Timmer, J., García-Jurado, I. and Borm, P.E.M. (2004). "Inventory Games," European Journal of Operational Research 156, 127-139.

Meca A., Guardiola, L.A., and Toledo A. (2007). "p-additive games: a class of totally balanced games arising from inventory situations with temporary discounts," TOP 15 (2), 322-340.

Meca, A. (2007). "A core-allocation family for generalized holding cost games," Mathematical Methods of Operation Research, vol. 65, issue 3, pp 499-517.

Montrucchio, L. and Scarsini, M. (2007). “Large newsvendor games," Games Econ. Behav. 58 (2), 316-337.

Mosquera, M.A., García-Jurado, I., and Fiestras-Janeiro M.G. (2007). “A note on coalitional manipulation and centralized inventory management," Annals of Operations Research 158, 183-188. 
Muller, A., Scarsini, M., Shaked, M. (2002). "The Newsvendor Game has a Nonempty Core”, Games Econ. Behav. 38, 118-126.

Nagarajan, M., Sošić, G. (2006). "Game-theoretic analysis of cooperation among supply chain agents: Review and extensions," European J Oper Res (Online November 3, 2006).

Owen, G. (1975). "On the core of linear production games," Mathematical Programming 9, 358-370.

Özen, U. Norde H., and Slikker M. (2005). “On the convexity of newsvendor games,” BETA Working Paper 131, TUE, Eindhoven, The Netherlands.

Özen, U. Erkip N., and Slikker M. (2006). "Profit division in newsvendor situations with delivery restrictions," BETA Working Paper 186, TUE, Eindhoven, The Netherlands.

Özen, U., Fransoo, J., Norde H., and Slikker M. (2007). “Cooperation between multiple newsvendors with warehouses," Manufacturing \& Service Operations Management (To appear).

Özen, U. (2007). "Collaboration between multiple newsvendors," Ph.D. Thesis, TUE, Eindhoven, The Netherlands.

Özen, U. and Sošić, G. (2006). "A multi-retailer decentralized distribution system with updated demand information," BETA Working Paper 193, TUE, Eindhoven, The Netherlands.

Rockafellar, R. and Wets, R. (1976). "Stochastic convex programming: relatively complete recourse and induced feasibility," Math. Programming 81, 301-325.

Sarmah, S.P., Acharya, D., Goyal, S.K. (2006) “Buyer vendor coordination models in supply chain management," European J. Oper. Res. 175, 1-15.

Shapley, L.S. (1967). “On Balanced Sets and Cores," Naval Res. Logist 14, 453-460.

Shapley, L.S. (1971). “Cores of Convex Games," Int. J. Game Theory 1, 11-26.

Shapley, L.S., Shubik, M. (1969)."On market games," J. Econ. Theory 1, 9-25.

Shapley, L.S., Shubik, M. (1972). “The assignment game,” Int. J. Game Theory. 1, 111-130.

Slikker, M., Fransoo J., and Wouters, M. (2001). "Joint Ordering in Multiple News-Vendor Situations: A Game Theoretical Approach," BETA Working Paper, TUE, Eindhoven, The Netherlands.

Slikker, M., Fransoo, J., Wouters, M. (2005). “Cooperation between multiple news-vendors with transshipments, " European J. Oper. Res. 167, 370-380.

Slikker, M., Van den Nouweland, A. (2001). Social Economic Networks in Cooperative Game Theory. Kluwer Academic Publishers, Boston.

Sprumont, Y. (1990). "Population MonotonicAllocation Schemes for Cooperative Games with Transferable Utility," Games Econ. Behav. 2, 378-394.

Tamir, A. (1992). "On the Core of Cost Allocation Games Defined on Location Problems, “ Transp. Sci. 27, 81-86.

Tersine, R.J. (1994). "Principles of Inventory and Material Management," Amsterdam: Elsevier North Holland.

Tijs, S.H., Meca, A. and López, M.A. (2005). "Benefit sharing in holding situations," European Journal of Operational Research 162, 251-269. 
Toledo, A. (2002). “Problemas de Inventario con Descuento desde la perspectiva de la Teoría de Juegos," Ph.D. Thesis, Universidad Miguel Hernández of Elche.

Van den Heuvel, W., Borm, P. and Hamers, H. (2007). "Economic lot-sizing games," European Journal of Operational Research 176, 1117-1130.

Wagner, H.M. and Whitin, T.M. (1958). "Dynamic Version of the Economic Lot Size Model," Manag. Sci. 5, 89-96.

Zangwill, W.I. (1969). "A backlogging model and multi-echelon model of a dynamic economic lot size production system- a network approach, " Management Science, vol 15, No. 9, 506-527.

Zhang J. (2007). "Cost Allocation for Joint Replenishment Models", Forthcoming in Operations Research.

Zipkin, P.H. (2000). "Foundations of Inventory Management," Mc-Graw-Hill Companies, Inc. 


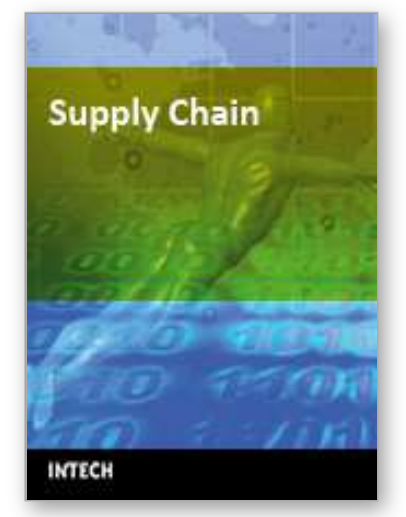

\author{
Supply Chain \\ Edited by Vedran Kordic
}

ISBN 978-3-902613-22-6

Hard cover, 568 pages

Publisher I-Tech Education and Publishing

Published online 01, February, 2008

Published in print edition February, 2008

Traditionally supply chain management has meant factories, assembly lines, warehouses, transportation vehicles, and time sheets. Modern supply chain management is a highly complex, multidimensional problem set with virtually endless number of variables for optimization. An Internet enabled supply chain may have justin-time delivery, precise inventory visibility, and up-to-the-minute distribution-tracking capabilities. Technology advances have enabled supply chains to become strategic weapons that can help avoid disasters, lower costs, and make money. From internal enterprise processes to external business transactions with suppliers, transporters, channels and end-users marks the wide range of challenges researchers have to handle. The aim of this book is at revealing and illustrating this diversity in terms of scientific and theoretical fundamentals, prevailing concepts as well as current practical applications.

\title{
How to reference
}

In order to correctly reference this scholarly work, feel free to copy and paste the following:

Ana Meca and Judith Timmer (2008). Supply Chain Collaboration, Supply Chain, Vedran Kordic (Ed.), ISBN: 978-3-902613-22-6, InTech, Available from:

http://www.intechopen.com/books/supply_chain/supply_chain_collaboration

\section{INTECH}

open science | open minds

\section{InTech Europe}

University Campus STeP Ri

Slavka Krautzeka 83/A

51000 Rijeka, Croatia

Phone: +385 (51) 770447

Fax: +385 (51) 686166

www.intechopen.com

\section{InTech China}

Unit 405, Office Block, Hotel Equatorial Shanghai

No.65, Yan An Road (West), Shanghai, 200040, China 中国上海市延安西路65号上海国际贵都大饭店办公楼 405 单元

Phone: +86-21-62489820

Fax: $+86-21-62489821$ 
(C) 2008 The Author(s). Licensee IntechOpen. This chapter is distributed under the terms of the Creative Commons Attribution-NonCommercialShareAlike-3.0 License, which permits use, distribution and reproduction for non-commercial purposes, provided the original is properly cited and derivative works building on this content are distributed under the same license. 